\title{
ESTUDO DA RELAÇÃO MOLAR IDEAL NA TRANSESTERIFICAÇÃO ETANOL:ÓLEO
}

\author{
ARAÚJO, A. P. ${ }^{1}$, GOUVÊA, C. A. K., COSTA, A. E. da Costa \\ ${ }^{1}$ Centro Universitário Tupy - Unisociesc, Faculdade de Engenharia Química \\ E-mail para contato: lec4_@hotmail.com
}

\begin{abstract}
RESUMO - O biodiesel é um combustível biodegradável com origem de fontes renováveis e pode ser obtido por diversos processos como craqueamento ou transesterificação. O presente trabalho buscou encontrar as melhores relações estequiométricas para a produção do biodiesel, variando a relação molar álcool:óleo em diferentes condições de adição de catalisador básico: preparado no momento da reação, na véspera e in situ. Como resultado, a relação mássica de excesso de etanol em 24:1 de óleo de soja virgem foi a única capaz de produzir biodiesel nas condições predeterminadas pela ANP, indiferentemente do momento da preparação do catalisador, na temperatura de $70^{\circ} \mathrm{C}$ no tempo de 2 horas.
\end{abstract}

\section{INTRODUÇÃO}

O biodiesel é um biocombustível, assim denominado pelo caráter renovável, de origem vegetal ou animal e tem um importante papel no aumento na oferta de energia no Brasil e no mundo. O biodiesel pode ser produzido de uma grande variedade de matérias-primas, que podem ser a maioria dos óleos vegetais, gorduras de origem animal e também óleo de fritura usado. Dependendo da origem e da qualidade da matéria-prima utilizada, mudanças no processo de produção são necessárias (Knothe et al., 2006).

O consumo desse combustível alternativo é crescente e estimulado por políticas públicas, demandando aporte de tecnologia para aumento da eficácia na reação. A reação de transesterificação realizada somente com catalisador básico demanda um tempo reacional longo, assim como elevadas temperaturas. A energia tem um custo elevado e, a possibilidade de condução da reação em temperaturas menores é favorável financeira e ambientalmente. De igual modo, o tempo de reação é importante para o aumento da produção e também para economia de energia.

Lopes (2008) estudou algumas variáveis de processo na produção e na purificação do biodiesel de soja via rota etílica, avaliando principalmente as relações molares de 1:4 e 1:10 de óleo e etanol, respectivamente. Como resultado, o rendimento da reação diminui 8,25\%, em média, quando a temperatura foi inferior a $70{ }^{\circ} \mathrm{C}$ e aumentou $17 \%$ quando a razão molar óleo de soja/etanol passou de 1:4 para 1:10. Observou também um aumento médio no rendimento de $12,25 \%$ quando a concentração de $\mathrm{NaOH}$ passou de $0,5 \%$ para $1,5 \%$, porém esse pesquisador encontrou aumento de apenas $1 \%$ quando o tempo de reação foi elevado de $0,5 \mathrm{~h}$ para $2 \mathrm{~h}$.

Assim, faz-se necessário estudar diferentes relações molares de etanol:óleo para que o rendimento da reação seja aumentado, bem como o tempo e temperatura possam ser 
otimizados. O objetivo geral da pesquisa é o estudo de diversas relações molares etanol:óleo e a consequente avaliação do rendimento da reação. Para atingir os objetivos do trabalho serão necessárias a realização das seguintes etapas:

1. Testar a transesterificação nas seguintes relações etanol:óleo 6:1, 12:1 e 24:1;

2. Testar a transesterificação nas seguintes condições de produção do alcóxido: no dia, na véspera e in situ;

3. Avaliar o tempo ideal de reação;

4. Determinar a cinética da reação utilizando a razão molar etanol:óleo 12:1.

\section{FUNDAMENTAÇÃO TEÓRICA}

O biodiesel teve grande ascensão com as preocupações com a escassez de combustíveis derivados do petróleo, ganhando destaque no Brasil a partir de 1970, onde criou-se o Pró-óleo - Plano de Produção de Óleos Vegetais para Fins Energéticos, originado de uma crise do petróleo da época. Desde aquele momento passou por uma desaceleração e atualmente o biodiesel tem a obrigatoriedade de ser adicionado ao diesel em cerca de $2 \%$ a partir de 2013 prevê-se pela Lei 11.097/2005, a introdução de 5\% de biodiesel em diesel (Ching eRodrigues, 2006). Já conhecido por sua aplicação em motores a diesel, o biodiesel apresenta em geral melhores eficiências dos motores, rendimento, redução de poluidores e redução do consumo de combustíveis (Costa e Oliveira, 2006).

Segundo a Lei $n^{0} 11.097$, de 13 de setembro de 2005, a definição para biodiesel seria "Biodiesel: biocombustível derivado de biomassa renovável para uso em motores a combustão interna com ignição por compressão ou, conforme regulamento para geração de outro tipo de energia, que possa substituir parcial ou totalmente combustíveis de origem fóssil" (Lei 11.097/2005).

Para produção do biodiesel duas rotas tecnológicas são amplamente difundidas e conhecidas, dentre elas as mais utilizadas são a transesterificaçãoe o craqueamento catalítico. O termo transesterificação é utilizado quando o método envolve uma catálise ácida ou básica, pois há uma dupla troca de acilgliceróis em ésteres de ácidos graxos. É comum a reação acontecer em temperaturas próximas de 45 a $60^{\circ} \mathrm{C}$ (Costa e Oliveira, 2006).

Em geral, são utilizados álcoois de cadeia pequena, como o álcool metílico e etílico, por permitirem a formação de um alcóxido quando em contato com a base. A manipulação do álcool metílico torna-se mais complicada devido ao seu caráter tóxico e o etanol, por sua vez, apresenta fontes renováveis de produção no Brasil. Quanto aos óleos, são glicerídeos formados, principalmente, por cadeias insaturadas (FERRARI et al., 2005).

A reação de transesterificação é realizada na presença de catalisadores ácidos, básicos ou enzimáticos, com as rotas com catalisadores básicos sendo as mais estudadas, embora a 


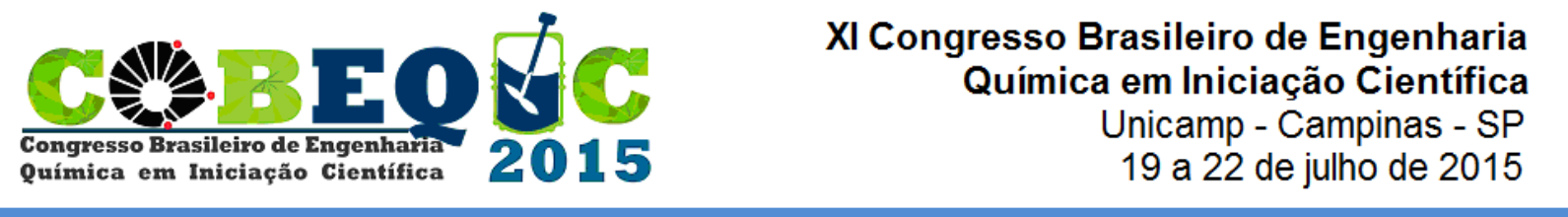

utilização de catalisadores ácidos favoreça uma menor produção de sabões, com retirada da água em excesso no começo do processo (Froehner et al., 2007).

O catalisador básico reage com o metanol ou etanol e forma alcóxido, que ataca as carbonilas dos glicerídeos, formando novos ésteres de cadeia menor. O rendimento da reação aumenta quando é utilizado um excesso estequiométrico do agente de transesterificação (alcóxido) e também com a otimização de outros fatores como temperatura e agitação (Milinsk, 2007).

\section{METODOLOGIA}

O biodiesel foi produzido utilizando a relação etanol:óleo de 6:1, 12:1 e 24:1, tendo como base $225 \mathrm{~mL}(250 \mathrm{~g})$ de óleo de soja virgem em béquer de $600 \mathrm{~mL}$, na temperatura de $70^{\circ} \mathrm{C}$, agitando por 120 minutos. Como catalisador, será utilizado o álcali hidróxido de sódio na relação de $1 \%$ em relação a massa de óleo em diferentes volumes de etanol de acordo com as relações estequiométricas propostas acima, agitados por 15 minutos a $60^{\circ} \mathrm{C}$ antes de adicioná-lo ao óleo. O álcali foi produzido em três condições; na véspera, no dia e in situ, com o objetivo de determinar qual apresenta a melhor eficiência na reação. Após a produção do biodiesel com as razões molares apresentadas acima, foi calculado o rendimento pela Equação 1 e realizada a caracterização do biodiesel produzido através da técnica de cromatografia gasosa.

\section{Rendimento $=$ volume de biodiesel $/$ volume inicial de óleo $\times 100$}

Após serem encontrados os melhores parâmetros da reação em relação às razões molares etanol:óleo e a condição do alcóxido, na continuidade do presente trabalho, serão realizados testes com variação do tempo. Após essa etapa, será feita uma curva cinética da mesma.

\section{RESULTADOS E DISCUSSÕES}

As reações de transesterificação utilizando diversas relações etanol:óleo foram executadas, correlacionando com as condições de obtenção do alcóxido; in situ, véspera e no dia, no tempo de 120 minutos, estando os resultados apresentados na Tabela 1. 
Tabela 1 - Resultados das Reações de Transesterificação

\begin{tabular}{|c|c|c|c|c|}
\hline \multirow{2}{*}{$\begin{array}{c}\text { RELAÇÃO } \\
\text { ÁLCOOL:ÓLEO }\end{array}$} & \multirow{2}{*}{ PARÂMETROS } & \multicolumn{3}{|c|}{ PREPARAÇÃO DO ALCÓXIDO } \\
\hline & & VÉSPERA & DIA & IN SITU \\
\hline & $\begin{array}{l}\text { Volume } \\
\text { (GLICERINA) }\end{array}$ & $140 \mathrm{~mL}$ & $135 \mathrm{~mL}$ & Não separou \\
\hline & $\begin{array}{l}\text { Volume } \\
\text { (BIODIESEL) }\end{array}$ & $105 \mathrm{~mL}$ & $110 \mathrm{~mL}$ & $255 \mathrm{~mL}$ \\
\hline & Densidade & $1,00 \mathrm{~g} / \mathrm{cm}^{3}$ & $1,00 \mathrm{~g} / \mathrm{cm}^{3}$ & Não separou \\
\hline & Teor $(\%)$ & 85,3 & 84,9 & Não separou \\
\hline & $\begin{array}{l}\text { Volume } \\
\text { (GLICERINA) }\end{array}$ & $60 \mathrm{~mL}$ & $66 \mathrm{~mL}$ & $60 \mathrm{~mL}$ \\
\hline & $\begin{array}{l}\text { Volume } \\
\text { (BIODIESEL) }\end{array}$ & $165 \mathrm{~mL}$ & $195 \mathrm{~mL}$ & $172 \mathrm{~mL}$ \\
\hline & Densidade & $0,88 \mathrm{~g} / \mathrm{cm}^{3}$ & $0,9 \mathrm{~g} / \mathrm{cm}^{3}$ & $0,87 \mathrm{~g} / \mathrm{cm}^{3}$ \\
\hline & Teor $(\%)$ & 93,5 & 93,1 & 92,7 \\
\hline & $\begin{array}{l}\text { Volume } \\
\text { (GLICERINA) }\end{array}$ & $95 \mathrm{~mL}$ & $68 \mathrm{~mL}$ & Não separou \\
\hline & $\begin{array}{l}\text { Volume } \\
\text { (BIODIESEL) }\end{array}$ & $180 \mathrm{~mL}$ & $195 \mathrm{~mL}$ & $272 \mathrm{~mL}$ \\
\hline & Densidade & $0,89 \mathrm{~g} / \mathrm{cm}^{3}$ & $0,87 \mathrm{~g} / \mathrm{cm}^{3}$ & $0,87 \mathrm{~g} / \mathrm{cm}^{3}$ \\
\hline & Teor (\%) & 98,1 & 97,6 & 97,4 \\
\hline
\end{tabular}

Em relação às condições de preparação do alcóxido, é possível obter duas conclusões. A primeira é que a condição in situ não é recomendável, pois por diversas vezes emulsiona o óleo na fase aquosa formada, impedindo a separação dessas, prejudicando assim o processo para a produção do biodiesel.

A segunda conclusão é que, apesar das diferenças de volume de biodiesel produzido com o alcóxido preparado na véspera e preparado no dia serem pequenas, é mais vantajoso utilizar o alcóxido produzido no dia. Chegou-se a essa conclusão baseado no volume de biodiesel obtido, pois este é maior do que em relação às outras razões testadas.

Observando os resultados obtidos em relação às diferentes razões molares utilizadas foi possível concluir que a única relação que atende ao definido pela ANP (Agência Nacional do Petróleo) na Lei $\mathrm{n}^{\circ} 11.097$ é a de $24: 1$, uma vez que esta obteve teor de ésteres sempre acima de $95 \%$, entre 97 e $98 \%$. 


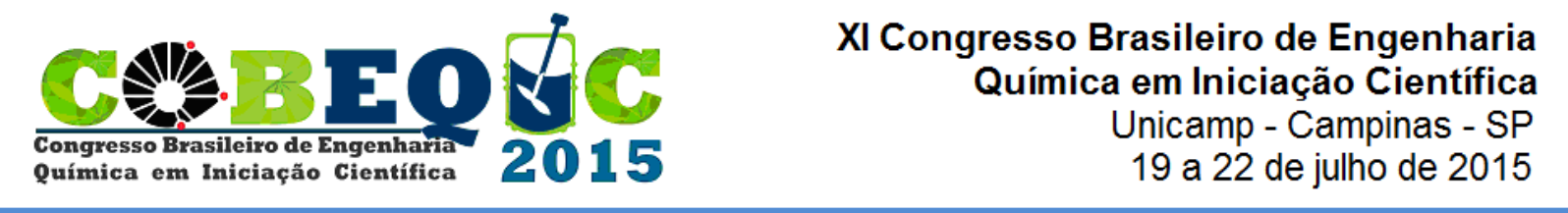

\subsection{VARIAÇÃO DO TEMPO NA RAZÃO MOLAR 12:1 COM ALCÓXIDO PRODUZIDO NO DIA}

Foram realizadas reações de transesterificação variando o tempo de reação, utilizando a relação etanol:óleo de 12:1 na condição do alcóxido produzido no dia. Os tempos testados foram o de 5, 15 e 120 minutos. Os resultados obtidos estão dispostos na Tabela 2.

Tabela 2 - Resultados das Reações de Transesterificação 12:1 com Variação do Tempo

\begin{tabular}{ccccc}
\hline $\begin{array}{c}\text { TEMPO DE } \\
\text { REAÇÃO }\end{array}$ & $\begin{array}{c}\text { VOLUME DE } \\
\text { GLICERINA }(\mathbf{m L})\end{array}$ & $\begin{array}{c}\text { VOLUME } \\
\text { BIODIESEL }(\mathbf{m L})\end{array}$ & $\begin{array}{c}\text { DENSIDADE } \\
\mathbf{( g / \mathbf { c m } ^ { 3 } )}\end{array}$ & TEOR (\%) \\
\hline $\mathbf{5}$ minutos & 55 & 188 & 0,87 & 7,3 \\
$\mathbf{1 5}$ minutos & 60 & 183 & 0,88 & 20,2 \\
$\mathbf{1 2 0}$ minutos & 66 & 195 & 0,9 & 93,1 \\
\hline
\end{tabular}

A realização dos testes utilizando a razão molar etanol:óleo de 12:1 permitirá obter a cinética da reação e, posteriormente, realizar um estudo com uso de catalisadores ácidos na fase óleo, com vistas no aumento do rendimento da reação, obtendo um teor de biodiesel dentro dos valores permitidos pela ANP, sem a necessidade de adicionar um excesso de álcool, que demanda energia para sua extração após a transesterificação.

\section{CONCLUSÃO}

Após a realização do estudo sobre as diversas relações molares etanol:óleo e a melhor condição de preparação do alcóxido, concluiu-se que a utilização de excesso do etanol na transesterificação aumentou o rendimento da reação de modo a atender as exigências da ANP e que as condições de preparação do alcóxido não alteram substancialmente a produção do biodiesel, porém a preparação do alcóxido in situ pode comprometer a separação das fases devido ao poder de emulsificação da base. Também foi possível afirmar que a densidade do biodiesel obtido não permite afirmar que a esterificação atende o teor de éster determinado pela ANP. Por fim a continuidade deste estudo, sobre a análise do tempo de reação de transesterificação da relação etanol:óleo de 12:1, utilizando catálise mista com adição de catalisador ácido na fase óleo, poderá levar à produção do biodiesel em atendimento à legislação em uma condição reacional otimizada. 


\section{REFERÊNCIAS}

AGÊNCIA NACIONAL DO PETRÓLEO - ANP. Resolução ANP Nº 7, de 19.3.2008 - DOU 20/03/2008. Disponível em: $<$ http://nxt.anp.gov.br/NXT/gateway.dll/leg/leis/2005/lei\%2011.097\%20$\% 202005 . \mathrm{xml}$ ?f=templates $\$ \mathrm{fn}=$ default.htm\&sync=1\&vid=anp:10.1048/enu $>$. Acesso em: 30 abr. 2014.

CHING, Wang H.; RODRIGUES, C. W. . Cartilha Sebrae Biodiesel. Rio de Janeiro: Sebrae, 2006. Disponível em: <http://www.biodiesel.gov.br/docs/Cartilha_Sebrae.pdf $>$. Acesso em: 14 abril de 2011.

COSTA, Bill J.; OLIVEIRA, Sonia M. M. Produção do Biodiesel. Paraná: Tecpar, 2006. Disponível em: <www.respostatecnica.org.br>. Acesso em: 03 maio. 2014.

FERRARI, R.A., OLIVEIRA, V.S., SCABIO, A. Biodiesel de soja - taxa de conversão em ésteres etílicos, caracterização físico-química e consumo em gerador de energia. Química Nova, Vol. 28, No 1, 19-23, 2005.

FROEHNER, S., LEITHOLD, J; LIMA JR, L. F. Transesterificação de óleos vegetais: caracterização por cromatografia em camada delgada e densidade. Química Nova, Vol. 30, No. 8, 2016-2019, 2007.

LOPES, Adriana C. O. Estudo das Variáveis de Processo na Produção e na Purificação do Biodiesel de Soja Via Rota Etílica. Dissertação de Mestrado, Programa de PósGraduação em Engenharia Química, Universidade Federal de Alagoas. Maceió: Universidade Federal de Alagoas, 2008.

KNOTHE, G.; GERPEN, J. V.; KRAHL, J.; RAMOS, L. P. Manual de Biodiesel. Blucher: São Paulo, 2006.

MILINSK, Maria C. Análise Comparativa entre Oito Métodos de Esterificação na Determinação Quantitativa de Ácidos Graxos em Óleo Vegetal. Tese de Doutorado, Programa de Pós-Graduação em Química, Departamento de Química do Centro de Ciências Exatas da Universidade Estadual de Maringá. Maringá: Biblioteca Central UEM, 2007. 